\title{
SPECIAL STRUCTURES OF SODIUM LAYER OBSERVED IN THE DAYTIME OVER BEIJING, CHINA
}

\author{
Yuan Xia ${ }^{1}$, Guotao Yang ${ }^{2 *}$, Jihong Wang ${ }^{2}$, Xuewu Cheng ${ }^{3}$, Faquan $\mathrm{Li}^{3}$ \\ ${ }^{1}$ School of Electronic Engineering, Nanjing Xiaozhuang University, Nanjing, Jiangsu 211171, China \\ ${ }^{2}$ State Key Laboratory of Space Weather, National Space Science Center, Chinese Academy of Sciences, \\ Beijing, 100190, China \\ ${ }^{3}$ State Key Laboratory of Magnetic Resonance and Atomic and Molecular Physics, Wuhan Institute of \\ Physics and Mathematics, Chinese Academy of Sciences, Wuhan, Hubei 430071, China \\ *Email: gtyang@nssc.ac.cn
}

\begin{abstract}
In this paper the observation of sodium $(\mathrm{Na})$ layer in mesosphere and lower thermosphere (MLT) region over complete diurnal cycles based on broadband Na lidar at Yanqing Station, Beijing, China $\left(40.5^{\circ} \mathrm{N}, 116^{\circ} \mathrm{E}\right)$ was reported. Faraday filters with dual-channel design were used in the lidar receiving unit to suppress the strong background light in the daytime, which allow observation of $\mathrm{Na}$ layer with an acceptable signalto-noise ratio (SNR) under sunlit condition. Several special structures of $\mathrm{Na}$ layer observed in the daytime was discussed. The simultaneous continuous observation of zonal wind by meteor radar was presented for comparison. These observation results can provide direct and reliable supports for the study of mesopause dynamics and solar effect on $\mathrm{Na}$ layer.
\end{abstract}

\section{INTRODUCTION}

Metallic Na layer in the mesopause region is a good tracer for studying atmospheric dynamics and photochemistry. Based on resonance fluorescence scattering of $\mathrm{Na}$ atoms, $\mathrm{Na}$ lidar can achieve the measurement of $\mathrm{Na}$ layer parameters with high temporal and vertical resolution, which effectively promotes the development of the scientific research of the middle and upper atmosphere [Krueger et al., 2015]. However, due to the severe interference of the strong solar background light on the received signal in the daytime, there are far fewer lidar observations of the Na layer in daytime than at night, which limit our understanding of the diurnal variations of $\mathrm{Na}$ layer, especially on its underside where neutral chemistry plays a major role [Clemesha et al., 2002; States and Gardner, 1999].
In this paper, the observation of $\mathrm{Na}$ layer over complete diurnal cycles based on the lidar of Chinese Meridian Project in Beijing was reported. The special structures of $\mathrm{Na}$ layer observed in the daytime, including sporadic $\mathrm{Na}$ layer (Nas) and the downward extension of the layer bottom side, were discussed.

\section{METHODOLOGY}

The resonant fluorescence lidar of Chinese Meridian Project in Beijing was upgraded to a double-laser beam system for $\mathrm{Na}$ layer and $\mathrm{K}$ layer measurements [Jiao et al., 2015; Wang et al., 2012]. The $589 \mathrm{~nm}$ laser for the detection of $\mathrm{Na}$ layer was generated by a pulsed dye laser which was pumped by a pulsed Nd:YAG laser with wavelength of $532 \mathrm{~nm}$. The output energy of 589 $\mathrm{nm}$ pulses was about $40 \mathrm{~mJ}$. Backscattered resonant fluorescence photons from $\mathrm{Na}$ layer were received by a Cassegrain telescope with a 1000 $\mathrm{mm}$ diameter primary mirror. Narrowband Faraday anomalous dispersion optical filters (FADOF) were used for $\mathrm{Na}$ lidar receiving to suppress sky background light [Chen et al., 1996], so that reliable $\mathrm{Na}$ echo signal can be obtained under sunlit condition, allowing diurnal continuous observation of $\mathrm{Na}$ layer. In order to obtain higher effective transmission of echo fluorescence signal in condition of guaranteeing background suppression, the filtering unit was designed with dual channels. The echo signal was splitted to horizontal and vertical polarization beams with a polarization beam splitter (PBS), and then combined with a polarization beam combiner (PBC) after each beam pass through a Faraday filter respectively, which allow echo fluorescence photons in both polarizations to be 
received at the same time, effectively improving the SNR of Na layer echo signal during the day.

The spatial and temporal resolution of raw data were $96 \mathrm{~m}$ and $33.3 \mathrm{~s}$ (corresponding to 1000 laser pulses integrated to produce a profile), respectively. The data was generally integrated 15 min. The main parameters of broadband $\mathrm{Na}$ lidar in YanQing, Beijing are presented in table 1.

Table 1. The main parameters of broadband $\mathrm{Na}$ lidar in YanQing, Beijing

\begin{tabular}{ll}
\hline Parameters & Value \\
\hline Laser wavelength & $589 \mathrm{~nm}$ \\
Laser energy & $\sim 40 \mathrm{~mJ}$ \\
Repetition rate & $30 \mathrm{~Hz}$ \\
Telescope aperture & $\Phi 1000 \mathrm{~mm}$ \\
Receiving field of view & $0.2 \sim 2 \mathrm{mrad}$ \\
Bandwidth of filter & $\sim 3 \mathrm{GHz}$ \\
Effective aperture of filter & $\Phi 15-18 \mathrm{~mm}$ \\
Range resolution (raw data) & $96 \mathrm{~m}$ \\
Time resolution (raw data) & $33.3 \mathrm{~s}$ \\
\hline
\end{tabular}

\section{RESULTS}

The diurnal operations of $\mathrm{Na}$ lidar have been conducted from May, 2014 and more than 4500 hours of observation data covering all months in a year over complete diurnal cycles were collected, which provides effective support for the study of the diurnal variation of $\mathrm{Na}$ layer and the formation mechanism of special phenomena occurred in $\mathrm{Na}$ layer. Figure 1 shows the distribution of observation hours of $\mathrm{Na}$ lidar in each month in the period from May, 2014 to December, 2016. According to the statistics, there are more than 30 campaigns with continuous data acquisition of longer than 48 hours, and more than 5 campaigns longer than 96 hours. Some examples of $\mathrm{Na}$ layer observed in daytime are as follows.

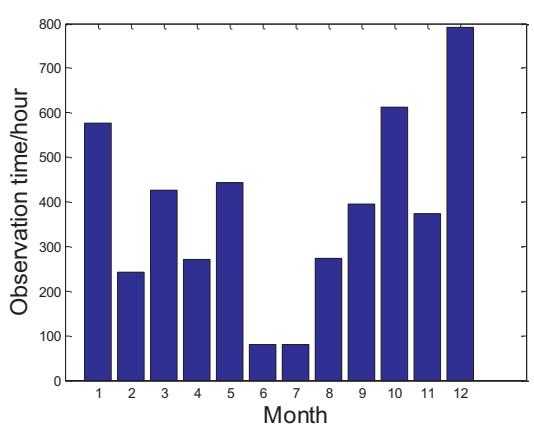

Fig. 1 The distribution of cumulative observation hours in each month of the broadband Na lidar of Yanqing Station, Beijing during the period of May, 2014 - December, 2016

\subsection{Sporadic sodium layers occurred in daytime}

Nas event is one of the research hotspots in the field of atmospheric and space physics, the diurnal observation of $\mathrm{Na}$ layer allows for a specialized analysis of Nas occurred in the daytime. An example of Nas events observed in the daytime of three consecutive days in August, 2016 is shown in Figure 2. As can be seen from the data sequences of the Na profiles in all three plots, the Nas events started in the morning or around noon, and the total process lasted for about 4-6 $\mathrm{h}$ (the $\mathrm{Na}$ profile from about 13:15 LT to $13: 30 \mathrm{LT}$ in $10^{\text {th }}$ August was removed due to the low SNR). The Nas occurred around the altitude between $95 \mathrm{~km}$ and $105 \mathrm{~km}$ with very strong density enhancements, especially during the day of August $8^{\text {th }}$. According to the statistical analysis of nocturnal Nas in Beijing by Jiao et al. [Jiao et al., 2015], the Nas descending times were generally longer than the ascending times. In contrast to this, as shown in Figure 2, both the Nas events observed in the daytime of $8^{\text {th }}$ and $9^{\text {th }}$ August have longer ascending times ( more than $3 \mathrm{~h}$ ) than descending times (less than $1 \mathrm{~h}$ ). 


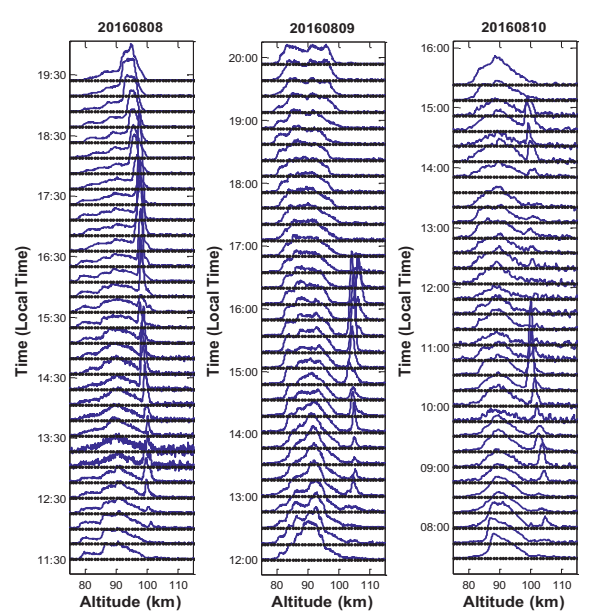

Fig. 2 Nas observed in the daytime for three consecutive days (each profile was integrated with $15 \mathrm{~min}$, and the spatial resolution is $96 \mathrm{~m}$ )

\subsection{The variations on the underside of $\mathrm{Na}$ layer in the daytime}

The altitude of Na layer is usually between $80 \mathrm{~km}$ and $105 \mathrm{~km}$. Lots of observation results have shown that Na layer generally rises steeply on the bottom side around $80 \mathrm{~km}$ and falls slowly on the topside around $105 \mathrm{~km}$. In recent years, the special phenomena on the topside of the sodium layer, such as the high-altitude Nas [Collins et al., 1996; Yuan et al., 2014] and the thermosphere Na layers[Dou et al., 2013; Xue et al., 2013; Tsuda et al., 2015; Gao et al., 2015], have been observed and studied by several groups. Besides, Gong et al. and Wang et al. reported the double sodium layers (DSL), which have secondary sodium layers (SeSL) above the normal layer [Gong et al., 2003; Wang et al., 2012]. More recently, Xun et al. reported neutral $\mathrm{Na}$ atoms layer at higher altitudes which extended to around $200 \mathrm{~km}$ over Beijing, China [Xun et al., 2019]. However, the distinctive structures on the underside of the sodium layer, have been rarely reported. Figure 3 is a contour of relative sodium density in time-altitude, which shows an obvious downward extension of the bottom of the sodium layer to around $72 \mathrm{~km}$ in the morning. The $\mathrm{x}$-axis in Figure 3 represents local solar time. As shown in Figure 3, the bottom side gradually decreased with time from about 4:30 LT, and lasted about $5 \mathrm{~h}$. By around 9:30 LT, the bottom of $\mathrm{Na}$ layer showed upward contraction. It is worth mentioning that the contraction process is faster than the extension process.

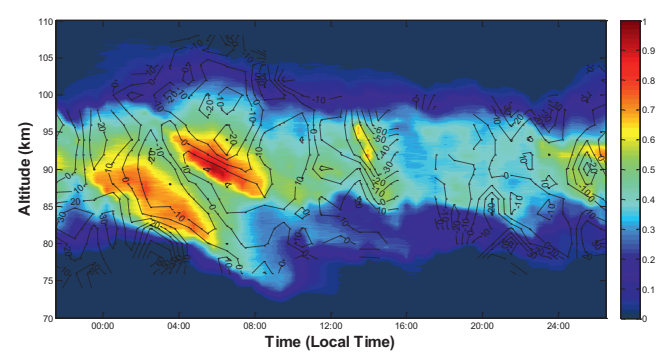

Fig. 3 Relative sodium density and simultaneous zonal wind measured by Radar. Sodium density are shown with color mapping scaled from 0 to 1 , winds are shown as contours with black lines.

The formation of metal atomic layers is considered to be controlled by the interaction of meteoric ablation injection, dynamical transport and chemical processes. This large-scale extension of the bottom side of $\mathrm{Na}$ layer started in the early morning of December in winter, which was quite different from the seasonal characteristics of the diurnal variation of Fe layer bottom side reported by $\mathrm{Yu}$ et al [Yu et al., 2012]. Moreover, the downward extension process of the $\mathrm{Na}$ layer did not last for the whole day, and it showed a fast upward contraction before noon, which was not linearly related to the variation of solar radiation. We may infer that there were some differences in the response of $\mathrm{Na}$ atoms and $\mathrm{Fe}$ atoms in the MLT region to solar radiation.

We can also find that the peak density of the $\mathrm{Na}$ layer in Figure 3 exhibits obvious downward tidal fluctuations propagation. We plotted the simultaneous zonal wind results measured by meteor radar, which was shown as contours with black lines in Figure 3 for comparison. The meteor radar was deployed in Beijing observation station of Institute of Geology and Geophysics Chinese Academy of Sciences (IGGCAS) $\left(116^{\circ} \mathrm{E}\right.$, $40^{\circ} \mathrm{N}$ ), which was very close to the YanQing $\mathrm{Na}$ lidar station. The radar wind data has a spatial resolution of $2 \mathrm{~km}$ and temporal resolution of $1 \mathrm{~h}$. As can be seen from Figure 3, from about 00:00 to 08:00 LT, the null point of the zonal wind with a westward wind above an eastward wind descended from around $90 \mathrm{~km}$ to $75 \mathrm{~km}$, and another null point with an eastward wind above an westward wind descended from around $95 \mathrm{~km}$ to $80 \mathrm{~km}$, which were similar to the evolution trends of the two peak altitudes of the $\mathrm{Na}$ layer in Figure 3. It is obvious that there is a close relationship 
between the zonal wind and the vertical distribution of $\mathrm{Na}$ layer.

These observation results can provide direct evidence for the study of the solar effects on the $\mathrm{Na}$ chemistry and tides in the mesosphere. However, the possible formation mechanisms may be complicated, and more case and statistical analyses and comparative studies combined with the joint observation data of other equipments such as ionosonde, meteor radar and satellite are needed.

\section{ACKNOWLEDGEMENTS}

This work was supported by the National Natural Science Foundation of China (No. 41627804), the Natural Science Foundation of the Jiangsu Higher Education Institutions of China (18KJB170009), Scientific Research Project of Nanjing Xiaozhuang University (4177022, 2018NXY46). We acknowledge the use of the data from the Chinese Meridian Project and World Data Centre for Geophysics, Beijing(http://wdc.geophys.ac.cn).

\section{REFERENCES}

[1] Collins R., Hallinan T., Smith R., et al. Geophys. Res. Lett., 23(24): 3655-3658 (1996)

[2] Chen H., White M.A., Krueger D.A. et al. Opt. Lett., 21:1003-1005 (1996)

[3] Clemesha B.R., Batista P.P., and Simonich D.M., J. Atmos. Sol. Terr. Phys., 64:1321-1325 (2002)

[4] Dou X.K., Qiu S.C., Xue X.H., et al. J. Geophys. Res., 118(10): 6627-6643 (2013)

[5] Gao Q., Chu X.Z., Xue X.H., et al. J. Geophys. Res., 120, 9213-9220 (2015)

[6] Jiao J., Yang G., Wang J., et al. J. Geophys. Res. Space Physics, 120: 5214-5225 (2015)

[7] Krueger D. A., She C. Y., and Yuan T. Appl. Opt., 54(32): 9469-9489 (2015)

[8] States R.J., and Gardner C.S. J. Geophys. Res., 104: 11783-11798 (1999)

[9] Tsuda T., Chu X, Nakamura T, et al. Geophys. Res. Lett., 42(10):3647-3653 (2015)

[10] Wang J., Yang Y., Cheng X., et al. Geophys. Res. Lett., 39, L15801 (2012)

[11] Xue X.H., Dou X.K., Lei J.H., et al. J. Geophys. Res. Space Physics, 118(5): 2409-2418 (2013)

[12] Xun Y., Yang G., She C., et al. Geophys. Res. Lett., DOI: 10.1029/2018GL081645 (2019)

[13] Yu, Z., X. Chu, W. Huang ,et al. J. Geophys. Res., 117, D22303 (2012)

[14] Yuan T., Wang J., Cai X., et al. J. Geophys. Res. Space Physics, 119(7): 5985-5999 (2014) 